\title{
HEMATOMAS NA FOSSA CRANIANA POSTERIOR
}

\author{
Mário S. CAdemartori *
}

Os hematomas da fossa posterior são raros em nossos serviços. Não tendo encontrado referências sôbre êles na bibliografia brasileira e verificando não serem muito freqüentes os registros na literatura estrangeira, resolvemos relatar alguns casos que tivemos oportunidade observar.

Hematomas subdurais crônicos - Contrastando com o grande número de hematomas extradurais traumáticos de fossa posterior, são raros os subdurais - 31 casos encontrados na literatura por Ciembroniewicz ${ }^{4}$ até 1965, aos quais o autor acrescentou mais três — e raríssimos os subdurais de evolução crônica.

Picken ${ }^{2 \tau}$ (1928) referiu um caso, em adulto, com evolução de três meses e diagnosticado mediante necrópsia. Gross ${ }^{15}$ (1955) referiu um caso, operado, com quatro meses de evolução. Poupre e col. ${ }^{29}$ (1957) relataram um casc, com um mês de evolução, operado com sucesso. Langfitt e McQueen ${ }^{19}$, Estridge e Smith ${ }^{12}$, Reigh e O'Connell ${ }^{30}$ fazem referências a casos de hematcmas subdurais decorrentes de traumatismos, inclusive de parto, já anteriormente referidos por Coblentz ${ }^{6}$ e por Nelson ${ }^{24}$. Norlén e col. ${ }^{25}$ ressaltaram que a hemorragia da fossa posterior no periodo perinatal é responsável por hidrocefalias comunicantes de evolução caprichosa ou por quadros agudos com agravamento rápido e morte.

A etiologia em 6 dos casos citados por Ciembroniewicz ${ }^{4}$ não foi determinada. Este autor cita Achesloger que, em 1952, sugeriu serem aneurismas ou malformações angiomatosas rôtas, as causas determinantes dos hematomas de evolução crônica. Em 1965, Wright e col. ${ }^{32}$ publicaram um caso referente a paciente que apresentou hemorragia subaracnóidea, com investigação supratentorial negativa; pela autópsia, 22 dias depois do episódio hemorrágico, foi verificada a presença de aneurisma rôto da artéria vertebral direita e hematoma.

O caso que passamos a relatar constitui achado operatório e teve como causa, pequeno traumatismo occipital.

Caso 1 - N.M.S., 19 anos, sexo feminino, internada em 1964 (Ficha 288). A paciente informou que, três meses antes, começara a ter cefaléia fronto-occipital; há 35 dias, distúrbios visuais e, nos últimos 15 dias, perda da visão total; há 10 dias a cefaléia se agravou muito, sendo acompanhada de vômitos freqüentes. Exame

* Assistente do Instituto de Neurocirurgia de Pôrto Alegre; Chefe de Clínica do Instituto de Neurocirurgia do Hospital Cristo Redentor. 
clínico-neurológico - Paciente lúcida, bem orientada, mas com déficit de memória. Pupilas em midriase; a reação foto-motora fraca à esquerda e ausente à direita; estase papilar com exudatos e focos hemorrágicos em ambos os olhos, alguns em fase de reabsorção. Exame de líquido cefalorraqueano - Punção lombar: pressão inicial 35 e final 25; líquido xantocrômico; 1,2 células por $\mathrm{mm}^{3}$; albumina $0,48 \mathrm{~g} / 1$. Na suposição de existir processo expansivo na fossa posterior, foi feita pneumoventriculografia com pequena quantidade de ar, sendo verificada moderada hidrocefalia e falha na repleção do aqueduto de Sylvius e do quarto ventriculo.

Operação - Paciente sentada, com apôio frontal. Ao ser aberta a dura-mater, fluiu liquido marron-escuro. Tratava-se de hematoma encapsulado, de forma triangular, com base na altura do atlas e vértice superior; lateralmente, aderida aos hemisférios no folheto visceral e não estava aderente à dura-mater, em nada se diferenciando dos hematomas subdurais supratentoriais. Foi ressecada a porção central do folheto visceral, sendo estabelecida continuidade com o espaço sub-aracnóideo.

Pós-operatório sem acidentes com rápida melhora da visão em $\mathrm{OE}$ e para a luz em OD; a última revisão da paciente, feita em 22-6-1965, mostrava atrofia óptica quase total à direita e parcial à esquerda. O exame histológico do folheto visceral mostrou "espessamento fibroso e inflamação crônica focal discreta." Os sintomas apresentados pela nossa paciente eram sòmente de hipertensão craniana, sem sinais de localização. Algum tempo depois do ato cirúrgico a paciente se lembrou ter sofrido traumatismo craniano, batendo com a região occipital em uma janela.

O estudo dêste caso e o confronto com o que é referido na literatura, permitem concluir que os hematomas subdurais da fossa craniana posterior podem evoluir de maneira:

(a) Aguda, como os produzidos por traumatismos de parto e contusões occipitais diretas. Naquêles, instalam-se ràpidamente sinais de comprometimento de tronco cerebral, convulsões tônico-clônicas, abaulamento de fontanelas, afastamento das suturas cranianas e aumento do perímetro craniano. Nos traumatismos diretos, destaca-se o intervalo lúcido, seguido de cefaléia, vômitos, deterioração rápida da consciência (de minutos a poucas horas) e coma profundo.

(b) $\$ u b-a g u d a$, como nos decorrentes de lesões perinatais e nos quais predomina a hidrocefalia por obstrução do trânsito do líquido cefalorraqueano e distúrbios de reabsorção. No caso de Coblentz ${ }^{6}$, o líquido cefalorraqueano era xantocrômico, havia hiperreflexia profunda e simétrica, sem déficits motores nem espasticidade; punções lombares mostraram líquido cefalorraqueano inicialmente hemorrágico e depois límpido, enquanto que a hidrocefalia aumentava. Registra-se, além de traumatismo, cefaléia, vômitos, rigidez de nuca, envolvimento de nervos cranianos. Sinais de sofrimento bulbar e a desintegração da consciência têm evolução mais lenta que nas formas agudas. Sinais cerebelares não são freqüentes. É quasi impossível diferenciá-lo, clìnicamente, dos extradurais.

(c) Crônica, determinando hidrocefalia comunicante em crianças e adultos: cefaléia de intensidade crescente, sonolência, vômitos, comprometimento da motricidade no dimídio corpóreo contralateral à lesão, engurgitamento venoso ou edema incipiente de papila, nistagno horizontal, ausência do reflexo faríngeo ${ }^{27},{ }^{29}$. A pressão do líquido cefalorraqueano pode ser normal, sen- 
do o líquido límpido, com aumento do teor de proteínas. Em nosso caso, acima exposto, os sintomas eram os comuns a qualquer moléstia que determine hipertensão intracraniana sem manifestações de localização.

O diagnóstico clínico deve ser relacionado a traumatismos anteriores, fratura occipital, ausência de patologia supratentorial e sinais de hipertensão na fossa posterior, tudo complementado por exames neuro-radiológicos.

$\mathrm{Na}$ etiologia são apontados: rotura de vasos drenando para os seios venosos, laceração de vasos arteriais e venosos da superfície cerebelar e rotura dos grandes seios venosos.

Hemorragias intra-cerebelares - As hemorragias cerebelares, tratadas cirùrgicamente e com sucesso são pouco referidas na literatura, pois, ou determinam ràpidamente o óbito ou, pela sua raridade ${ }^{2,28}$ não figuram habitualmente no diagnóstico diferencial com as demais hemorragias do encéfalo. Em geral constituem achados de necrópsia (0,44\% em 4.526 autópsias e 204 hemorragias intracranianas ${ }^{2}$ ). Para McKissock e col. ${ }^{21}$ representariam $10 \%$ das hemorragias do encéfalo. Conforme Loeb et Meyer ${ }^{20}$, no cerebelo, a região próxima aos núcleos, é um dos sítios mais comuns de hemorragias, opinião que contrasta com a dos demais autores. São raros os casos publicados com definitiva suspeita clínica, confirmação radiológica e cirúrgica $^{1,21 .}$

Caso 2 - L. R., branco, sexo masculino, 54 anos (Ficha 1.080). Em 18-5-1965 o paciente despertou com cefaléia, vômitos e insegurança na marcha. No dia seguinte cessaram os vômitos e a cefaléia diminuiu, persistindo o desequilíbrio, acompanhado de vertigens quando movimentava a cabeça. No quarto dia a cefaléia aumentou de intensidade, passando o paciente a vomitar freqüentemente, a queixar-se de fotofobia, não conseguindo deambular devido a acentuado desequilíbrio. Antecedentes - Paciente com moderada hipertensão arterial que já sofrera três enfartes do miocárdio. Exame clínico-neurológico - Paciente consciente e orientado. Decúbito preferencial esquerdo. Os movimentos passivos e espontâneos do segmento cefálico provocam náuseas. Discreta lateralização para a esquerda na marcha. Pressão arterial Mx 140, Mn 80 . Pulso com $86 \mathrm{~b} . / \mathrm{min}$. Cinco dias depois, nítido desvio da marcha para a esquerda. Desvio espontâneo do indicador para o mesmo lado. Na mesma noite, vômitos, nistagmo horizontal (componente lento para a esquerda) e vertical. Fundos oculares: moderados sinais de angioesclerose. No sexto dia, paralisa dos movimentos oculares de verticalidade superior. Exame do liquido cefalorraqueano: punção lombar em decúbito lateral; pressão inicial 25, pressão final 12; manobra de Queckenstedt mostrando passagem franca; líquido xantocrômico; proteínas $0,90 \mathrm{~g} / 1 ; 3,3$ leucócitos e 210 hemácias por $\mathrm{mm}^{3}$; reações de Nonne-Appelt e Pandy positivas; reação de Takata-Ara positiva, de tipo misto. No mesmo dia, acentuada sonolência. Hiperemia dos bordos nasais das papilas ópticas. Miose bilateral. Reflexos plantares em extensão. No sétimo dia, estado de coma, pulso 54 p./min, respiração com ritmo de Cheyne-Stokes, temperatura de $38^{\circ} \mathrm{C}$, rigidez de nuca e hipotonia generalizada.

A evolução sub-aguda, com cefaléia, vômitos, vertigens, disfunção cerebelar, síndrome de Parinaud, líquido cefalorraqueano xantocrômico, hipertensão intracraniana e conservacão da consciência até surgirem sinais de envolvimento do tronco cerebral nos orientaram topogràficamente para a fossa posterior. o angiograma carotideo à direita mostrou sinais discretos de hidrocefalia. O angiograma vertebral direito mostrou estar o tronco basilar deslocado para a frente (fig. 1). O iodoventriculograma mostrou estar o lipiodol retido parcialmente no aqueduto de Sylvius, sendo êste dilatado superiormente e estrangulado no $1 / 3$ inferior (fig. 1). 

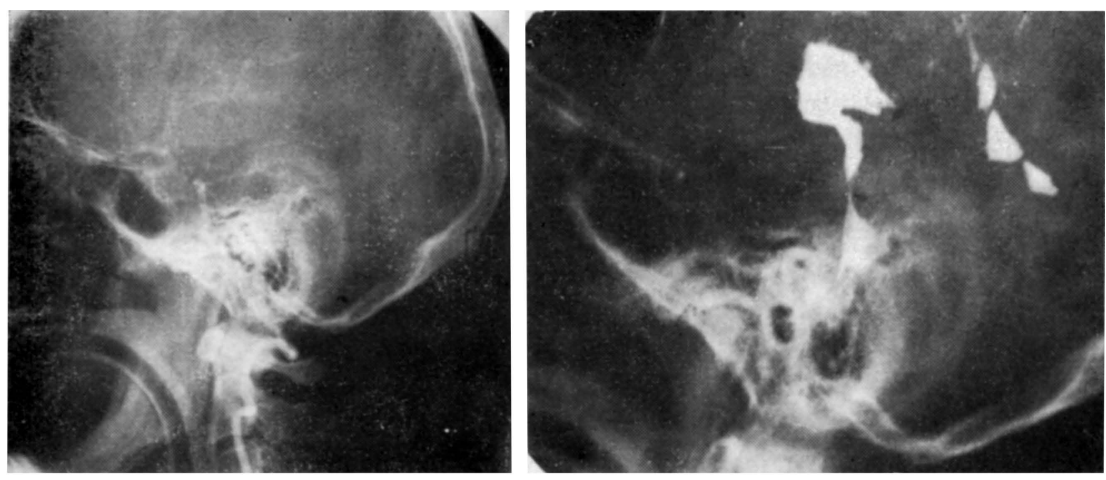

Fig. 1 - Caso 2. À esquerda, arteriografia pela artéria vertebral evidenciando deslocamento do tronco basilar para a frente; à direita, iodoventriculografia mostrando estar o aqueduto de Sylvius parcialmente interrompido e o IV ventrículo desviado no sentido antero-posterior.

O paciente foi operado, tendo sido encontrado hematoma cerebelar no hemisfério esquerdo, para-mediano, com volume aproximado de $15 \mathrm{~cm}^{3}$. A cavidade se prolongava superiormente, não tendo sido encontrados vasos anômalos nem sangrantes. Pós-operatório sem complicações. Alta no oitavo dia com regressão completa dos sintomas. Quatorze dias depois da alta, o paciente sofreu nôvo enfarte do miocárdio, vindo a falecer.

Caso 3 - J. F., branco, sexo masculino, 39 anos, internado em 8-8-1965 (Ficha 1082). Há 40 dias, durante atividades costumeiras, o paciente fôra acometido de cefaléia frontal súbita, vertigens e vômitos. Desde então, não consegue mais andar, vomita freqüentemente e, há 5 dias, está com o pescoco rigido. Estas informaçōes foram colhidas com auxílio dos familiares, pois embora lúcido, o paciente elaborava lenta e dificilmente. Exame clínico-neurológico - Paciente desidratado. Pressão arterial Mx 110, Mn 70. Pulso 68 b./min. Temperatura $35,5^{\circ} \mathrm{C}$. Palavra discretamente escandida. Astasia-abasia. Pupilas isocóricas. Reflexos fotomotores e consensuais presentes. Paralisia dos movimentos oculares de verticalidade superior e laterais. Fundos oculares: estase papilar. Fôrça muscular diminuída à direita e hemiparesia do mesmo lado. Embora o paciente pouco colabore, registra-se tremor grosseiro, assinergia e dismetria à direita. Hipotonia generalizada. Acentuada rigidez de nuca. Leve diminuição do reflexo patelar direito. Exame do líquido cefalorraqueano: pressão inicial 38, pressão final 25; líquido xantocrômico; proteínas $0,48 \mathrm{~g} / \mathrm{l} ; 9,3$ leucócitos e 95 hemácias por $\mathrm{mm}^{3}$. Pneumencefalografia: hidrocefalia e desvio do quarto ventriculo para a esquerda. Iodoventriculografia: sinais superponiveis (fig. 2).

Intervenção cirúrgica em 12-8-1965 - Craniectomia occipital com o paciente sentado. Foi encontrado abaulamento superior direito do teto do quarto ventrículo, de onde fluia líquido viscoso, vermelho e marron-escuro. A punção permitiu colhêr $4 \mathrm{ml}$ de líquido hemático contendo coágulos. A exploração com espátula possibilitou evacuar hematoma liquefeito, restando uma cavidade de cêrca de $10 \mathrm{~cm}^{3}$. Pós-operatório sem complicações. A angiografia pela artéria vertebral, realizada poucos dias antes da alta, em 4-9-1965, revelou malformação vascular na fossa posterior. 

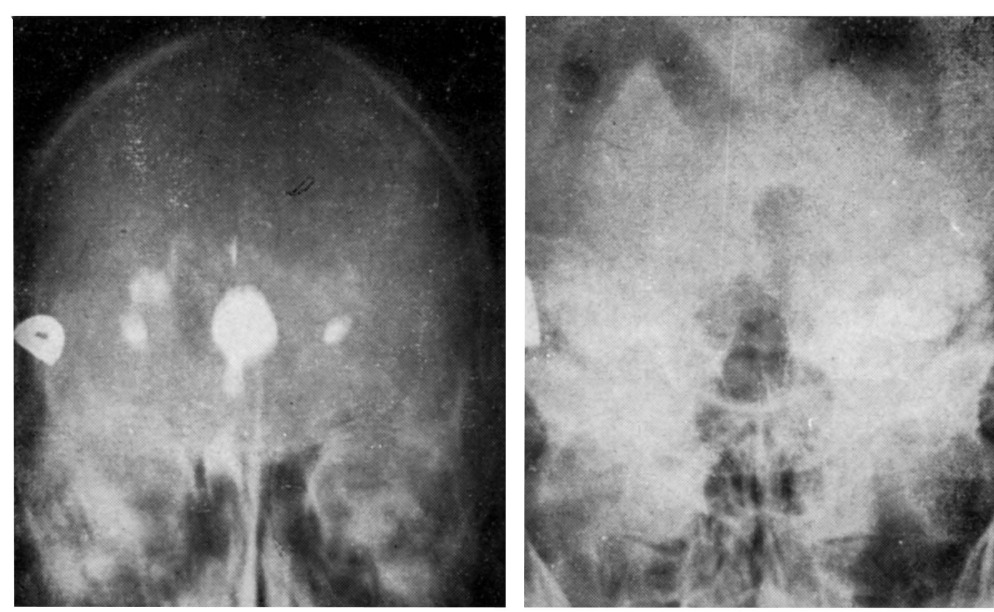

Fig. 2 - Caso 3. À esquerda, iodoventriculografia mostrando obliteração parcial do aqueduto de Sylvius, estando o IV ventrículo com repleção incompleta e desviado lateralmente; à direita, pneumencefalograma mostrando desvio do IV ventrículo para a esquerda.

CASo 4 - L.E.G., branca, 23 anos, bancária, internada em 7-4-1969 (Ficha 5916), informando que 10 dias antes, durante leitura, fôra acometida de cefaléia generalizada, vertigens e vômitos; êstes últimos sintomas regrediram depois de algumas horas, persistindo a cefaléia. Exame clínico-neurológico - Marcha com discreto aumento do poligono de sustentação, relativa imobilidade do segmento cérvico-cefálico, meningismo, nistagmo horizontal, intenso ao olhar para a direita e fraco ao olhar para a esquerda, dismetria nos segmentos do dimídio direito. $O$ exame de fundo de ôlho não mostrou alterações. Exame de líquido cefalorraqueano: punção lombar; líquido xantocromico; pressão inicial 30 , pressão final 18; 3,2 células e 24,8 hemácias por $\mathrm{mm}^{3}$; albumina $0,41 \mathrm{~g} / 1$; cloretos $6,78 \mathrm{~g} / 1$; glicose $0,47 \mathrm{~g} / 1$; reações de Pandy e Nonne positivas; reação de Takata-Ara positiva, tipo floculante. Arteriografia pela artéria vertebral direita não revelou anormalidade. A paciente ficou em observação e, como a cefaléia aumentasse de intensidade, voltando a apresentar vômitos em 12-4-1969, foi feita nova punção lombar, cujos resultados se aproximam do primeiro exame. Em 25-4-1969 foi feita a pneumencefalografia, não sendo obtida repleção ventricular. Em 29-4-69 foi feita iodoventriculografia que mostrou desvio do $4 .^{\circ}$ ventrículo para a esquerda.

A paciente foi submetida à trepanação de fossa posterior, sendo encontrada aracnóide espessada, leitosa, não permitindo saída de liquor. Ressecada a mesma foi visualizada a amigdala cerebelar direita e hemisfério do mesmo lado que estavam aumentados de volume. A punção do hemisfério permitiu atingir, a dois centímetros de profundidade, cavidade contendo líquido hemático da qual foram retirados $8 \mathrm{~cm}^{3}$ de hematoma misto. A paciente convalesceu normalmente, tendo tido alta em 9-5-1969.

Neste caso, fica mais uma vez evidenciado o fato, de que o estudo do sistema vértebro-basilar não mostrando anormalidade não exclui a possibilidade de processo expansivo na fossa posterior.

Caso 5 - J.V.O., 29 anos, sexo masculino, internado em 30-12-1964 (Ficha 401). Há 14 dias, quando trabalhava, sentiu borramento da visão no OD e intensa cefaléia, entrando logo em estado de coma. Exame clínicóneurológico - Paciente 
em coma; pupilas mióticas e isocóricas; estase papilar bilateral; paralisia facial direita, supra-nuclear; acentuado meningismo; o pinçamento da região mamária direita provocava sinais de descerebração, em extensão, à direita; reflexos profundos muito diminuídos; retenção de secreção na orofaringe. Respiração estertorosa, com 26 mov./min. Pressão arterial Mx 130, Mn 80 . Pulso $100 \mathrm{~b} . / \mathrm{min}$. Temperatura $38,4^{\circ} \mathrm{C}$. Exame do liquido cefalorraqueano: punção lombar; liquido fracamente hemorrágico. Angiografia carotidea direita: sinais de hidrocefalia. Angiografia pela artéria vertebral direita: shunt envolvendo ramos laterais da artéria cerebelosa posterior e inferior (fig. 3).
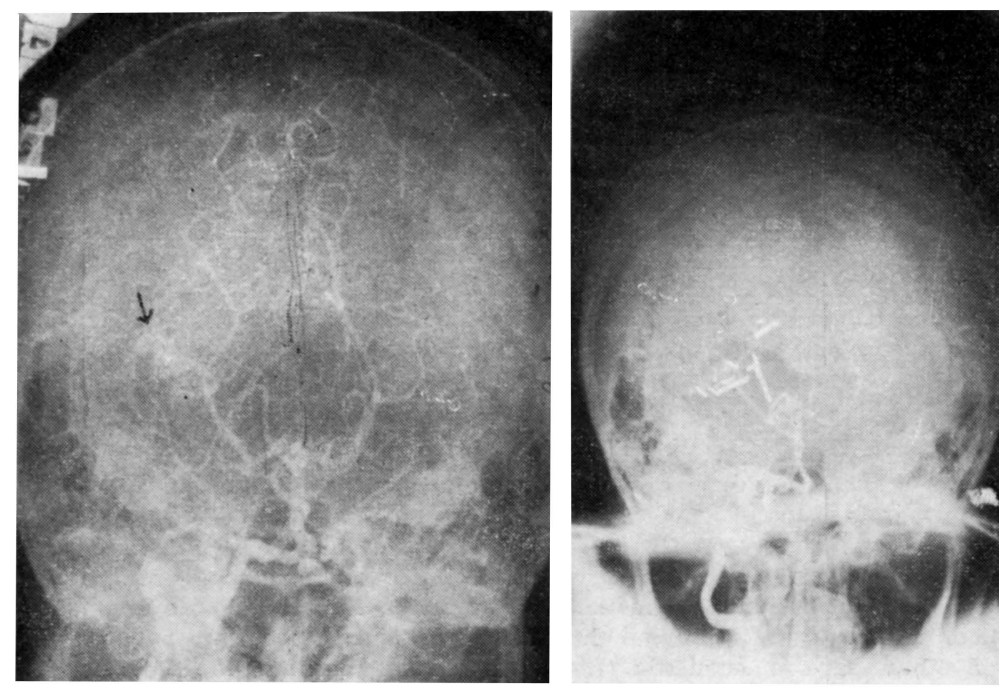

Fig. 3 - Caso 5. À esquerda, angiografia pela artéria vertebral mostrando malformação irrigada principalmente por ramo da artéria cerebelosa posterior $e$ inferior; à direita, angiografia pós-operatória mostrando exclusão parcial do angioma.

Intervenção cirúrgica em 31-12-1965 - Tronco cerebral desviado para a esquerda, comunicação do hematoma com a corticalidade cerebelar direita. Esvaziando o mesmo, restou cavidade do tamanho de um ôvo de galinha, dentro da qual se verificou a presença de malformação nutrida especialmente por ramos da artéria cerebelosa posterior e inferior e drenada para o seio lateral. Foram colocados clipes nos pedículos considerados como principais. Pós-operatório com infecção pulmonar, evoluindo satisfatòriamente. Alta em 19-1-1966. Em 25-3-1966, o paciente foi reinternado para contrôle e nova angiografia pela artéria vertebral mostrou persistência do angioma. Reoperado, foi submetido a nôvo contrôle em 16-7-1966, que mostrou exclusão da malformação (fig. 3). Em dezembro de 1966 o paciente retornou ao trabalho.

Hematoma extra-dural - São freqüentes as publicações na literatura estrangeira sôbre os hematomas extradurais $1,7,16,17,30$, como o que ocorreu no caso que passamos a relatar. 
CASi 6 - N.J.S., branco, 10 anos, sexo masculino, internado em 10-4-1965 (Ficha 879). O paciente foi atropelado em via pública, tendo ficado inconsciente por tempo indeterminado. Atendido em serviço hospitalar de urgência, foi medicado e mandado para casa. Apresentando, no mesmo dia, cefaléla e vômitos, foi internado no Instituto de Neurocirurgia. Exame clinico-neurológico — Paciente lúcido, cooperando bem. Moderada rigidez de nuca. Exame dos fundos oculares: ausência de pulso venoso. Radiografias de crânio sem alterações. No dia seguinte o paciente apresentava hemiparesia esquerda com reflexo cutâneo-plantar em extensão. A cefaléia aumentou de intensidade e o paciente ficou agitado, mas consciente. No terceiro dia após o acidente, apresentava bradicardia, extrasistoles respiraçāo irregular, ritmo de Cheyne-Stokes. No mesmo dia foi feita angiografia carotídea direita que mostrou estarem os vasos arteriais e venosos em posição anatômica. No dia seguinte a temperatura se elevou, ambos os reflexos plantares davam resposta em extensão, o sofrimento respiratório se acentuou e a frequiência do pulso baixou para 40 batimentos por minuto. Ao ser transportado para o gabinete radiológico para novos exames, o paciente apresentou sinais de descerebração bilateralmente e, logo a seguir, teve parada respiratória. Entubado e com respiração assistida, sofreu trepanação da fossa posterior, sendo encontrado volumoso hematoma extra-dural mediano, expandindo-se lateralmente, bem como pequeno hematoma subdural e, à direita, contusāo cerebelar. Não se encontrou fratura. Esvaziado o hematoma, houve recuperação do automatismo respiratório e melhora imediata dos sinais vitais. Alta em 23-4-1965 com normalidade neurológica.

No caso 1, hematoma sub-dural de evolução sub-aguda, gradual (podendo ser enquadrado no segundo grupo de Michael, citado por McKissock), os sinais neurológicos advindos após iniciada a cefaléia e freqüentes vômitos, são topogràficamente precisos e seguem um gradiente definido de agravamento clínico: disfunção cerebelar, sofrimento do mesencéfalo e, finalmente, comprometimento bulbar. Neste caso concordamos com Bellet em que o tamanho da lesão não explicaria, senão por compressão secundária, as manifestações finais.

O paciente do caso 2 (hematoma intracerebelar), operado 44 dias após a eclosão da sintomatologia é o de mais longa evolução, dentro da literatura compulsada e enquadra-se no terceiro grupo de Michael e no terceiro de Thomas (1927), citado por Loeb e Meyer ${ }^{20}$. Julgamos que tão longa e incomum evolução estaria na dependência da rotura do hematoma para dentro do quarto ventrículo, diminuindo a compressão e mantendo o quadro clínico estacionário. Têm sido relatados achados de necrópsia com lesões cicatriciais antigas ${ }^{13,20}$ no cerebelo, o que demonstra a possibilidade de evolução espontânea favorável. É provável que no nosso caso, a comunicação da cavidade hemática para o IV ventrículo tivesse iniciado evolução para a cura, apenas acelerada pela intervenção cirúrgica.

No caso 3 (hematoma no IV ventrículo), o conjunto dos sintomas e sinais poderiam ser atribuidos à sua etiologia - aneurisma artério-venoso - além de permitir a decisão quanto à sua operabilidade. No caso 4 tratava-se de hemorragia intracerebelar cuja causa não pôde ser esclarecida. Embora Olivecrona, em 1923, tenha operado, com sucesso, malformação de fossa craniana posterior, sòmente casos isolados vêm sendo publicados ${ }^{23}$, 
com excessão de Dereux e col. ${ }^{10}$ que, em 1959 relataram 9 casos, distinguindo clìnicamente as malformações do tronco cerebral das cerebelares, e de Morello e Borghi ${ }^{22}$ que, em 1963, também relataram 9 casos operados, dos quais cinco com sucesso. Êstes últimos autores consideram inoperáveis os angiomas que envolvem o tronco cerebral. Malformações vasculares, na fossa posterior, como a existente no nosso caso 5 , são raramente suspeitadas e, se não romperem, são de diagnóstico difícil 5, 8, 22. Elas podem determinar sintomatologia simulando esclerose em placas, tumor da fossa posterior com quadro de hipertensão intracraniana e com déficit piramidal ou cerebelar progressivo e, ainda, comprometimento de nervos cranianos ou tumores de desenvolvimento rápido ${ }^{10,11}$. Conforme Krayenbuhl, a localização de malformações vasculares infratentorais é de $6,2 \%$ e raramente estão associadas a outras patologias 18. As manifestações clínicas têm início entre 12-17 anos, para Hyland (citado por Ciminelo e Sacha ${ }^{5}$ ), entre 15-41 anos para Morello e Borghi ${ }^{22}$ e, nos casos de Dereux e col. ${ }^{10}$, dos 15 aos 46 anos. As malformações vasculares podem estar situadas na corticalidade ou no vermis cerebelar ou na ponte e determinar sindrome cerebelo-piramidal homolateral, síndrome de Millard-Gubler ou de Parinaud ${ }^{23}$. O episódio hemorrágico determina um quadro de apoplexia, coma, meningismo, sintomas cerebelares, comprometimento de nervos cranianos, envolvimento piramidal unilateral e, raramente, sindrome alterno. São também freqüentes hemianopsia, anisocoria, nistagmo moderado e diplopia 10,22, 26. Os angiomas do tronco cerebral, além de determinar lesões piramidais e sensitivas bi ou unilaterais, comprometem maior número de nervos cranianos e determinam paralisia dos movimentos oculares de verticalidade, ao passo que os do cerebelo causam sindrome cerebelar, déficit piramidal homolateral e envolvimento de nervos motores oculares uni ou bilateral. Em nosso caso, como nos de alguns autores citados, é fácil a confusão com hemorragias supratentoriais e a angiografia vertebral bilateral foi capaz de estabelecer o diagnóstico. $O$ hematoma pode ainda comprimir a malformação e impedir sua contrastação.

Os critérios para o diagnóstico dos hematomas extra-durais, conforme Coleman e col. ${ }^{7}$, se baseiam em: 1) ocorrência de traumatismo e existência de fratura; 2) cefaléia de aumento gradual, acompanhada de náuseas e vômitos; 3) obnubilação progressiva; 4) posição antálgica da cabeça; 5) rigidez de nuca; 6) nistagmo espontâneo; 7) arreflexia profunda; 8) hipotonia muscular; 9) inconsciência final, irregularidades no pulso e na respiração, ameaça de morte iminente. Campbell e col. ${ }^{3}$ destacam que, na evolução, pode haver quadro agudo, após intervalo lúcido, com evolução para o coma, dificuldades respiratórias, sinais de descerebração e morte dentro de poucas horas; também pode ocorrer um quadro sub-agudo, com hipertensão craniana combinada com disfunção cerebelar e/ou bulbar, com agravamento progressivo. Os sintomas bulbares, para Hooper ${ }^{16}$, evoluem em 24 horas nos casos agudos, em 2-7 dias nos casos sub-agudos; nos casos crônicos, a evolução é mais lenta. O diagnóstico deve ser estabelecido pela anamnese (ocorrência de traumatismo occipital com ou sem fratura) e pela evolução, sendo complementado por exames paraclínicos. 
Para o diagnóstico de lesão hemática determinando hipertensão na fossa posterior, julgamos ser necessário ter em mente os sinais e sintomas agrupados por McKissock e col. ${ }^{21}$ : início súbito (28 casos), sem perda de consciência (18 casos) ou inconsciência iniciando entre 12 horas e 3 dias depois. Bellet ${ }^{2}$, em trabalho sôbre 21 casos, destaca que êste tipo de acidente vascular incide em pacientes com mais de 40 anos de idade, com início dramático, sendo constante a presença de coma ou estupor, podendo haver queixas de perda de consciência, náuseas e vômitos, vertigens, às vêzes sudorese, disartria, colapso e, mais raramente, sintomas cerebelares (25\% para McKissock); ao exame, conforme êste mesmo autor, podem ser assinalados coma ou estupor, anormalidades pupilares que vão desde a midríase e ausência do reflexo fotomotor, pupilas puntiformes predominantemente, respiração estertorosa e ritmos anormais, desvios conjugados dos olhos, comprometimento motor uni ou bilateral e, menos freqüentemente, hipotonia generalizada, ausência de reflexos corneanos e sinais cerebelares. A punção lombar revela líquido cefalorraqueano hemorrágico em elevada percentagem dos casos. Como a morte advém ràpidamente por compressão das estruturas vizinhas e, considerando que as seqüelas são muito mais benignas do que as determinadas por hemorragias cerebrais tratadas cirùrgicamente, a investigação deve ser procedida sem perđa de tempo. Ao nosso ver, quando houver suspeita clínica, o exame inicial deverá ser a angiografia pela artéria vertebral, seguida, se necessário, de pneumo ou iodoventriculografia. Em nossos casos foi necessário lançar mão de diversos métodos semióticos, pois, considerados individualmente, todos forneceram dados parcelados e insuficientes; só em conjunto tais exames permitiram conclusão e decisão final. A intervenção cirúrgica deverá ser efetuada sem delongas.

Pela revisão de nossos casos de hematomas da fossa craniana posterior e dos apresentados na literatura, concluímos que o diagnóstico dos hematomas subtentoriais, sejam traumáticos, espontâneos ou por rotura de malformação, exige criteriosa utilização de recursos semióticos clínicos e para-clínicos. Para o diagnóstico de localização e etiológico é indispensável estudo angiográfico pelas artérias vertebrais e, se necessário, pneumencefalografia fracionada ou iodoventriculografia. Estes exames devem ser feitos sucessivamente e sem delongas, afim de que o tratamento cirúrgico seja efetuado com a máxima brevidade.

\section{R E S U M O}

São relatados 6 casos de hematomas sub-tentorias (um de hematoma subdural crônico, quatro de hematomas intra-cerebelares, um de hematoma extra-dural). Salientando a pequena freqüência dos hematomas da fossa craniana posterior, o autor mostra a necessidade de vários exames complementares para o diagnóstico exato, indispensável para a aplicação de terapêutica cirúrgica adequada. 


\section{S U M M A R X}

\section{Haematomata in the posterior foss $\alpha$}

Six cases of sub-tentorial haematomata (one chronic sub-dural, four intra-cerebellar, one extra-dural) are reported. Emphasizing the relative rarity of haematomata in the posterior cranial fossa, the author claims the necessity of complementary examinations for proper diagnosis, indispensable for adequate surgical treatment.

\section{R E F E R E N I A S}

1. ARONSON, H.; SHAFEY, S. \& GARGANO, F. - Intracerebellar haematoma. J. Neurol. Neurosurg.Psychiat. 28:442-444, 1965.

2. BELLET, R. J. - Cerebellar haemorrhage: a clinical-pathologic study. Neurology (Minneapolis) 10:217-222, 1960.

3. CAMPBELL, E.; WHITFIELD, R. \& GREENWOOD, R. - Extradural haematomas of the posterior fossa. Ann. Surgery 138: 509-519, 1953.

4. CIEMBRoNiEWICZ, J. E. - Sub-dural haematoma of the posterior fossa. Review of the literature with addition of three cases. J. Neurosurg. 22:465$473,1965$.

5. Ciminello, V. J. \& SACHA, J. E. - Arteriovenous malformation of the posterior fossa. J. Neurosurg. 19:602-604, 1962.

6. COBLENTZ, B. G. - Cerebellar sub-dural haematoma in infant two weeks old with secondary hyprocephalus. Surgery 8:771-776, 1940.

7. COLEMAN, C. C.; THOMSON, J. L. \& RICHMOND, V. A. - Extradural haemorrage in the posterior fossa. Surgery 10:985-990, 1941.

8. CRAWFORD, J. V. \& RUSSEL, D. S. - Cryptic arteriovenous and venous haematomas of the brain. J. Neurol. Neurosurg. Psychiat. 19:1-11, 1956.

9. DAVIDOFF, L. M. - Surgical treatment of spontaneous intracerebral haemorrhage. Second Max Dauzis Memorial Lecture, Newmark Beth Israel Hosp. $4: 22,1956$.

10. DEREUX, J.; MAYRAC, P.; LANIE, E., GALIBERT, P.; DELAUDTSHEER, J. M.; PRUVOT, P.; RIFF, G. \& DEBERT, R. - Neuf anéurysmes artérioveineux de la fosse postèrieure: étude clinique et thèrapeutique. NeuroChirurg. (Paris) 5:257-279, 1959.

11. DEREUX, J.; DEREYMACKER, A.; DELBERGHE, P. \& DEBERT, R. Anéurysme artério-veineux de la fosse postérieure: angle ponto-cérebelleux. Rev. Neurol. (Paris) 100:56-58, 1959.

12. ESTRIDGE, M. V. \& SMITH, R. A. - Acute sub-dural haemorrhage of posterior fossa: report of a case with review of the literature. J. Neurosurg. 18:248$249,1961$. 
13. FISCHER, C. M. - The Pathology of Cerebrovascular Diseases. In Pathogenesis and Treatment of Cerebrovascular Diseases. W. S. Fields, editor. Charles C. Thomas, Springfield (Illinois), 1961.

14. GERLACH, J. Von \& JENSEN, H. P. - Die intracerebralen Haematome bei Mikroangiome. Act. Neurochir., 7:367-373, 1961.

15. GROSS, S. W. - Posterior fossa haematomas. Mount Sinai Hosp. (New York) 22:286-289, 1955.

16. HOOPER, R. S. - Extradural haemorrhages of the posterior fossa. Brit. J. Surg. 42:19-26, 1955.

17. KESSEL, F. K. - Cerebellar extradural haematoma. J. Neurol. Psychiat., 5:96-100, 1942.

18. KRAYENBUHL, H. - Discussion des rapports sur "Les angiomes supra-tentoriels". Act. Med. Belg. I Int. Congr. Neurosurg. págs. 263-267, 1957.

19. LANGFITT, T. W. \& McQUEEN, D. - Chronic extra-dural haematoma of the posterior fossa: a case with a diagnostic pneumoencephalografic finding. Neurology (Minneapolis) 18:215-217, 1957.

20. LOEB, C. \& MEYER, J. S. - Strokes Due to Vertebro-Basilar Disease. Charles C. Thomas, Springfield (Illinois), 1965.

21. McKISSOCK, W.; RICHARDSON, A. \& WALSH, L. - Spontaneous cerebellar haemorrhage: a study of 34 consecutive cases treated surgically. Brain 83: $1-9,1960$.

22. MORELlo, G. \& BORGHI, G. P. - Les angiomes sous-tentoriels: contribuition clinique. Neuro-Chirurgie (Paris) 9:446-451, 1963.

23. MOUNT, L. A. - Arteriovenous angioma derived from the anterior inferior cerebellar artery: its diagnosis and treatment. J. Neurosurg. 22:612-615, 1956.

24. NELSON, T. Y. - Acute subdural haematoma in the posterior fossa. Med. J. Australia 2:792-794, 1959.

25. NORLÊN, G.; RADBERG, G. \& GRANHOLM, L. - Infantille hydrocephalus and haematoma in the posterior fossa: presentation of case. J. Neurosurg. 21:309-310, 1964 .

26. ODOM, G. L.; TINDALL, G. T. \& DUKES, H. T. - Cerebellar haematoma caused by angiomatous malformations. J. Neurosurg. 18:777-782, 1961.

27. PICKEN, C. B. - A case of sub-dural haematoma. Guy's Hosp. Rep. 78:368$370,1928$.

28. POOL, J. L, \& POTTS, D. G. - Aneurysmes and Arteriovenous Anomalies of the Brain: Diagnosis and Treatment. Harper \& Row Publishers, Hoeber Medical Division, New York, 1965.

29. POURPRE, M. H.; TOURNOUX, P. \& REBUFFAT, P. - Hématomes sousduraux de la fosse postérieure. Neuro-Chirurgie (Paris) 3:200-202, 1957.

30. REIGH, E. E. \& O'CONNELL, T. Y. - Extra-dural haematoma of the posterior fossa with concomitant supratentorial sub-dural haematoma: report of a case and review of the literature. J. Neurosurg. 19:359-364, 1962. 
218 ARQ. NEURO-PSIQUIAT. (SÃO PAULO) VOL. 2\%, N.9 3, SETEMBRO, 1969

31. TOMASI, P. F.; GIRAUD, J. \& VAUZELLE, J. L. - Malformation vasculaire et lipome latéro-pontin. Neuro-Chirurgie (Paris) 9:440-446, 1963.

32. WRIGHT, J. R.; SLANIS, R. E. \& WAGNER, J. A. - Intracranial aneurysm as a cause of sub-dural haematoma of the posterior fossa. J. Neurosurg. 22:86-89, 1965.

Rua Silva Jardim 650, Pôrto Alegre, Rio Grande do Sul, Brasil. 